\title{
Designing with, through, and for Human-Nature Interaction
}

\author{
Szu-Yu (Cyn) Liu \\ Indiana University \\ Bloomington, IN 47408 USA \\ cynliu@iu.edu
}

\begin{abstract}
Human-nature interaction, joining the agendas of sustainable interaction design and nonanthropocentric $\mathrm{HCI}$, takes up the challenges presented by climate change and environmental crisis. My dissertation research focuses on studying sustainable farming practices through posthuman concepts to experiment ways of designing with, through, and for human-nature interaction. Specifically, my work aims to discover and develop alternative design paradigms and practices for sustaining both human and non-human life.
\end{abstract}

Permission to make digital or hard copies of all or part of this work for personal or classroom use is granted without fee provided that copies are not made or distributed for profit or commercial advantage and that copies bear this notice and the forll citation on the first page. Copyrights for

components of this work owned by others than ACM must be honored. Abstracting with credit is permitted. To copy otherwise, or republish, to post on servers or to redistribute to lists, requires prior specific permission and/or a fee. See rightsreview form for your actual text. Request permissions from permissions@acm.org.

DIS '19 Companion, June 23-28, 2019, San Diego, CA, USA (C) 2019 Association for Computing Machinery. ACM ISBN 978-1-4503-6270-2/19/06 ..\$15.00 https://doi.org/10.1145/3301019.3324874

\author{
Author Keywords \\ Human-nature interaction; posthuman; decentering \\ humans; sustainable HCI; sustainable agriculture.
}

\section{CSS Concepts}

- Human-centered computing $\rightarrow$ Interaction design theory, concepts and paradigms

\section{Research Situation}

My research focuses on human-nature interaction and sustainable agriculture to attend to the challenges associated with environmental crisis. Specifically, I engage in posthuman theories and investigate through on the ground experimental farming, collaborative food making, decomposition in agriculture, and design to explore ways of working with nature, as opposed to controlling or working against it (figure 1). Building on my on-going ethnographic study on small-scale, sustainable farming practices in Taiwan and Indiana, my works propose decentering the human in design- I combine together posthuman literature, critical qualitative methodologies, and research through design to envision more ethical and responsible ways of engaging in technological interventions. This line of research has led to a series of top-tier ACM conference publications, including CHI2019 [12], TEI2019 [13], DIS2018 [10], and LIMITS2018 [11]. In Summer 2019, I will join the Urban Innovation Initiative at Microsoft 


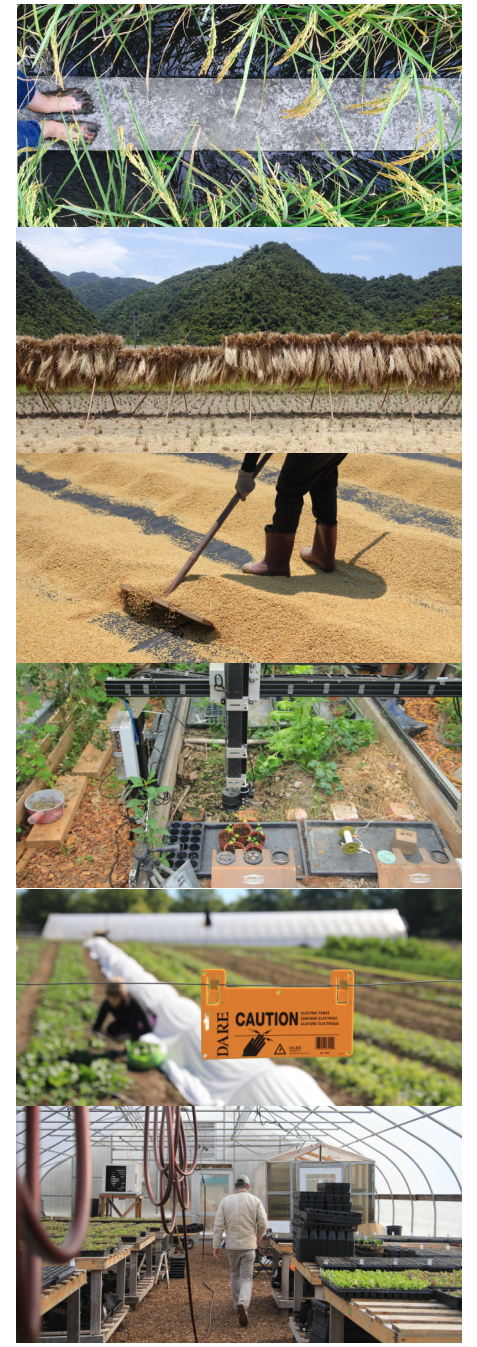

Figure 1: Ethnographic works in small-scale, sustainable farms in Yilan, Taiwan and Indiana, USA.
Research as an intern to build new technologies for sustainable urban environments. Following my previous works, the goal of my dissertation is to develop alternative design paradigms to think about how technology can better connect human with nature.

\section{Context and Motivation}

Prior to my doctoral studies, I was a product designer at an international personal computer design firm in Taiwan. Having witnessed truck after truck of hardware and electronic waste being transported to landfills every year, I am committed to forging together a stronger connection between design practices and environmental sustainability. I build on the values and frameworks of sustainable $\mathrm{HCI}$, grounded on my ethnographic work on eco-friendly farming experiments. However, I push for a broader definition of sustainability by bringing to the forefront the moments "when species meet" [4]; I am interested in exploring the possibilities and challenges in decentering the human in interaction design.

To do so, I turn to posthuman theories which consider humans, nonhumans, culture, and nature as intricately entangled and thus challenges the taken-for-granted ontological boundaries $[5,6]$. My research draws substantially on anthropologist Anna Tsing's theoretical concept, "arts of noticing", to see "the divergent, layered, and conjoined projects that make up worlds" [18:22], to cultivate the ability to acknowledge and simultaneously step in and out of familiar frames of reference $[8,12]$, and to imagine alternative futures by questions about "what is and what can be" [1].

\section{Background and Related Works}

Two interaction design research communities emerged with the attempt to address challenges associated with environmental crisis through design: sustainable HCI and nonanthropocentric HCI. Within the corpus of sustainable interaction design, studies on sustainable agriculture are increasing of interest for it offers the opportunities to move from individual persuasive technological design towards addressing the broader socioenvironmental challenges associated with food production, distribution, and consumption $[2,14]$. More recently, scholars in nonanthropocentric $\mathrm{HCI}$ reflect on the limits of human-centric design and argue the need to establish an alternative design agenda to encompass the multispecies worldview [17]; this body of research provides insight into nurturing interspecies cohabitation [16], collaboration [3], and collaborative survival $[7,9]$.

Posthuman concepts are particularly useful in resisting falling into habitual anthropocentric perspectives; as STS scholar Puig de la Bellacasa puts, "they enrich our perception of the complex articulations of agency, decentering individual human agency and considering the social as a tissue of associations between humans, nonhumans, and objects working in the realisation of new relational formations." [15:7]. However, the ability to move from automatic perceptions toward seeing the entanglement between human and nature is not easily cultivated; to Tsing, to "notice differently" requires shifting attention between multiple threads of a relationship [18].

With the interest in designing with, through, and for human-nature interaction, my interest is to translate abstract posthuman concepts into more trackable interaction design theories or actionable design strategies. For example, in [13], my co-authors and I unpack through Haraway's posthuman theory natureculture the process of decomposition. Through a 


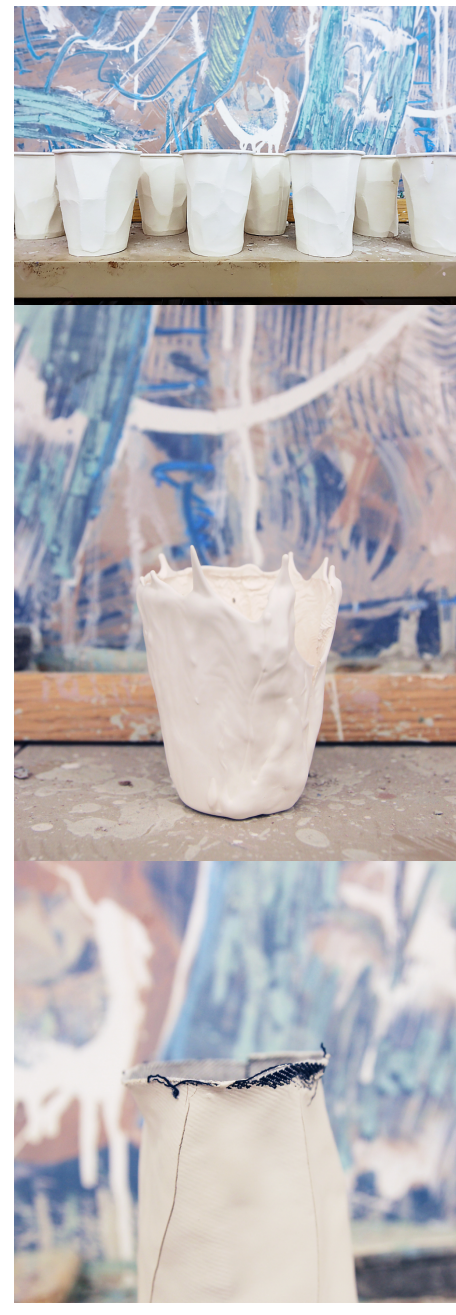

Figure 2: A series of ceramics experiments using the notion of decomposition to facilitate natureculture co-creation. series of design curation, analysis, and experiment, we propose "scaffolding" and as an interaction design theory accompanied by its actionable tactics for those who are interesting in natureculture co-creation. In $[11,12]$, we report our 2-year ethnography working alongside with small-scale farmers and how we learn to see weeds and pests as companions. Through embodied understanding of the earth, we reflect on ways of cultivating intimacy with the biosphere with and through technology.

\section{Research Goals and Methods}

When human activities render resource exhaustion, species extinction, and other forms of conflicts between humans and the environment, new ways of noticing, responding, and imagining are needed to move toward to preferable futures. As a result, the methods involve in my dissertation research are multifold, including qualitative social science methods (e.g., ethnography, interviewing, observation, and artifact analysis), artbased inquiry methodologies (e.g., research through design and speculative design), and approaches originated from the humanities (e.g., interaction criticism and close reading).

My on-going ethnography focuses on sustainable farming experiments, including eco-friendly farming, small-scale farming, organic farming, and AgTech. Common across these practices is the farmers' commitment to explore and practice the alternatives to industrial agriculture, with a particular focus on reducing the use of pesticides in farming and integrating more harmonious between land, people, environment, and resources. In these alternative farming practices, the farm is not so much a controlled system but an assemblage characterized by multiple systems or rationalities always evolving and changing. By working alongside with the farmers, I reflect on posthumanist values and learn to "notice differently".

Based on my dissertation research, I am developing "arts of noticing" as appropriate for interaction design research, that is, to think through posthuman lens how technology can better support resilient communal life. In [10], my co-authors and I combine together visual thinking and critical reflection to "see" the theoretical concept of natureculture by capturing through photographs different interfaces of human-nature interaction. In [13], the posthuman concept natureculture is further consolidated through a series of design-based inquiry approaches and materialized using ceramics as a medium (figure 2 ). Very recently, I experiment embodied knowledge as yet another way of knowing. In reflecting the encounters I have with ecofriendly farmers, animals, plants, and soil [12], I look into nontraditional users (e.g., nonhumans) and emerging forms of uses (e.g., interactions between human and other species) to help open a design space for technological interventions.

Building on my previous ethnographic and design works, I am currently designing a sensory sound box for deployment that tracks different attributes of compost (e.g., temperature, humidity, biometric movement) and translate the digital readings into music compositions. Through this design, I wish to explore a more embodied and aesthetic form of humannature interaction. The next stage of my dissertation research involves further consolidating posthuman concepts into interaction design theories by creating, deploying, and reflecting on interactive artifacts and farming tools. 


\section{Acknowledgements}

I thank my advisors, Jeffrey Bardzell and Shaowen Bardzell, for their mentorship and continuing support. I also thank my committee members, Eli Blevis and Barbara Dennis, for their insightful feedback. This work is supported in part by Taiwan's Ministry of Education and the NSF under award \#1513604.

\section{References}

[1] Eli Blevis. 2018. Seeing What Is and What Can Be: On Sustainability, Respect for Work, and Design for Respect. In CHI '18, Paper No. 370.

[2] Jaz Hee-jeong Choi and Eli Blevis. 2010. HCI \& sustainable food culture: A design framework for engagement. In NordiCHI '10, 112-117.

[3] Laura Forlano. 2016. Decentering the Human in the Design of Collaborative Cities. Design Issues 32, 3: 42-54.

[4] Donna Haraway. 2008. When Species Meet. University of Minnesota Press, London.

[5] Donna J Haraway. 2016. Staying with the Trouble: Making Kin in the Chthulucene. Duke University Press.

[6] Joanna Latimer and Mara Miele. 2013. Naturecultures? Science, Affect and the Nonhuman. Theory, Culture \& Society 30, 7-8: 5-31.

[7] Ann Light, Alison Powell, and Irina Shklovski. 2017. Design for Existential Crisis in the Anthropocene Age. In C\&T '17, 270-279.

[8] Silvia Lindtner, Shaowen Bardzell, and Jeffrey Bardzell. 2018. Design and Intervention in the Age of "No Alternative." Proceedings of the ACM on Human-Computer Interaction 2, CSCW: Article 109.

[9] Jen Liu, Daragh Byrne, and Laura Devendorf.
2018. Design for Collaborative Survival : An Inquiry into Human-Fungi Relationships. In CHI'18, 1-13.

[10] Szu-Yu (Cyn) Liu, Jeffrey Bardzell, and Shaowen Bardzell. 2018. Photography as A Design Research Tool into Natureculture. In DIS '18, 777-789.

[11] Szu-Yu (Cyn) Liu, Shaowen Bardzell, and Jeffrey Bardzell. 2018. Out of Control: Reframing Sustainable HCI Using Permaculture. In LIMITS '18, Article No. 2.

[12] Szu-Yu (Cyn) Liu, Shaowen Bardzell, and Jeffrey Bardzell. 2019. Symbiotic Encounters: HCI and Sustainable Agriculture. In CHI'19.

[13] Szu-yu Cyn Liu, Jeffrey Bardzell, and Shaowen Bardzell. 2019. Decomposition as Design: CoCreating (with) Natureculture. In TEI ' 19.

[14] Juliet Norton, Nico Herbig, Lynn Dombrowski, Ankita Raturi, Bonnie Nardi, Sebastian Prost, Samantha McDonald, Daniel Pargman, Oliver Bates, Maria Normark, and Bill Tomlinson. 2017. A grand challenge for $\mathrm{HCI}$ : food + sustainability. Interactions 24, 50-55.

[15] María Puig de la Bellacasa. 2010. Ethical doings in naturecultures. Ethics, Place and Environment 13, 2: $151-169$

[16] Nancy Smith, Shaowen Bardzell, and Jeffrey Bardzell. 2017. Designing for Cohabitation: Naturecultures, Hybrids, and Decentering the Human in Design. In CHI'17, 1714-1725.

[17] Vanessa Thomas; , Christian Remy, and Oliver Bates. 2017. The Limits of HCD: Reimagining the Anthropocentricity of ISO 9241-210. In LIMITS '17 Proceedings of the 2017 Workshop on Computing Within Limits.

[18] Anna Tsing. 2015. The Mushroom at the End of the World. Princeton University Press. 